\title{
Impacts of Job Stress and Dissatisfaction on Turnover Intention. A Critical Analasys of Logistics Industry - Evidence from Vietnam
}

Submitted 12/09/20, 1st revision 10/10/20, 2nd revision 29/10/20, accepted 20/11/20

\author{
Huynh Thi Thu Suong ${ }^{1}$
}

\begin{abstract}
:
Purpose: This paper's purposes are to recognize relations between job stress, dissatisfaction, and intention to quit the job of employees at Logistics enterprises in Vietnam (VLE). The job stress's determinants that have been tested by this research include roles of leadership, work relationship, work pressure, and time pressure.

Methodology/Approach: To conduct this study, the author has used qualitative and quantitative research methods to adjust and inspect the scales, models of theory showing its relations and impacting factors. This study is examined on a valid sample of 331 among 378 employees currently working in VLE. Using Confirm Factor Analysis, Structural Equation Modeling (SEM) with AMOS to affirm variables' relationship. Research findings disclose a close connection between the constructs of the model.

Findings: This study strongly confirms three scales of the variables: "job stress," "job dissatisfaction," and "turnover intention" remain valid and reliable. Moreover, there has been a significant relationship between them. From the research results, managers in VLEs have to be aware of and identify harmful factors affecting employees, thus preventing them from quitting the job. If there is a timely and appropriate solution, it would decrease job dissatisfaction and improve their commitment.

Originality/Value: Shaping employee turnover intention shows a certain dynamic in the way employees' function in the organization. The fact is that changes in the area of resources and requirements modify individual employees and the organization's function. Additionally, this research proposes a better insight into the process of dissatisfaction mediates the interconnection between organizations' etiquette and employees' behavior, with special reference to the logistics sector in Vietnam.
\end{abstract}

Keywords: Job stress, turnover intention, Logistics industry, Vietnam

JEL Classification: D22; J28; J29

Paper type: Research paper

\footnotetext{
${ }^{1}$ Faculty of Business Administration, University of Finance and Marketing huynhthusuong@ufm.edu.vn
} 


\section{Introduction}

An estimated over 300,000 logistics enterprises in which 54\% are in HCMC are in great demand for their workforce. Over 2 million employees in this sector will be required by 2030. In recent years, thanks to the development of logistics services, VLEs have made dramatic progress and showed a remarkable potential for growth (VLA, 2019). In 2016, being ranked 39 among 160 investigated countries, Vietnam has upped 25 rankings by 2019. Thanks to the government's effective policies and strategies and the constant attempt of VLEs, the logistics industry has such an achievement. To enhance the workforce and continue to face huge challenges, it has to evaluate the quality and quantity of this workforce and improve strategies to develop sustainability. In fact, the number of employees intending to leave their job due to working pressure is currently increasing (VLA, 2019). In 2019, according to the latest survey of Mercer-Talentnet on the quit rate in Vietnam, the three industries with the highest proportion of employees were the retail sector $(32.2 \%)$, real estate sector (18.8\%), and consumer goods sector (17.3\%). Although this industry does not belong to any of these major sectors, it has faced many challenges, such as the requirement of modern technology knowledge and technical skill, which are also vital given that new IT is increasingly being applied. Therefore, the significant number of employees who leave a job has increased rapidly. In fact, the biggest problem is stress at work, which has increased noticeably nowadays (Bashir and Ramay, 2010). For the logistics segment, work conditions have changed remarkably. Most of them are concerning technology and methodology changes which have made employees stressed. Previous researchers supposed most of the work pressure is caused by the shortage of managerial supports and suffered from the stuffy working atmosphere; consequences of such conditions might be harmful effects on employee's behavior and organizational performance (Arshadi and Damiri, 2013). Staff who endure such pressure will not feel happy, motivated, productive, and safe at work. The most important impact is that it directly affects employees' dissatisfaction, which will lead to turnover intention. Like other industries, VLEs aim to increase productivity and loyalty and improve their human resources by providing a good working environment and innovative leaders. To accomplish these important goals, VLEs face challenges, most of which are solving job quitting problems and improving the workforce's skills to respond to the competitive business sector. Due to an increasingly fierce competition environment, VLEs have many requirements for their staff. These challenging issues put pressure on employees and accumulate into job stresses. Thus, if there is no suitable method, it will negatively affect the business's operation, and more than anyone else, managers at VLEs must identify these challenges and then come up with suitable solutions.

\section{Literature Review}

\section{a. Job stress}

This term is believed to be a person's psychology having feelings and emotional experience linked to their working environment (Yang and Carayon, 2007). In other 
words, when an individual feels that "the demands surpass the personal and social capital, that person can mobilize, "a status of intense difficulty, distress, or offense is named as the greatest stress and risk. Stress is a feeling experienced. Stress is a behavioral, emotional, mental, and physical response process triggered by prolonged, growing, or new stresses that are substantially greater than the availability of coping strategies (Robbins and Stephen, 2004). Stress is also the consequence of an employee who faces requirements, pressure, and negative reactions that cannot match their level of knowledge, raising challenges and threats to employees' viability. Bashir and Ramay (2010), stress is thought to be a psychological form of individuals when faced with chaos, conflicts between personal needs, responsibilities, opportunities, and demands. This research will focus on working, especially employees' stress while working for their organization.

At work, many people blame high anxiety levels on bosses, jobs, deadlines, or other tasks that also want to take up their time. However, there are colleagues whom themselves face the same challenges without any stress. In my opinion, pressure does not totally stress, however, pressure can become stressful if there are additional factors, including reflection, which tends to think back and forth over past or future events while attaching negative emotions to those thoughts. In other words, one problem can be stressful for one person but not a big deal for others. This view leads to prevention strategies aimed at workers and how to support them to cope with working conditions. "Work-related stress," by some estimates, charges the national economy a staggering amount in sick leave, loss of productivity, health insurance, and cost of litigation (Palmer et al., 2004). Job stress is concluded to be anxiety or nervousness related to the job, which impacted employees' emotional and working behavior (Lu and Kuo, 2016). This conclusion implies that employees react in different ways whenever subjected to certain stressors. Whether it is psychosocial or physical, the employee must consider the stressor as excessively stressful. Components belong to job stress including Work pressure, Time pressure, Relationships pressure, Relationships pressure.

\section{b. Work pressure}

Considered as one of the top stress factors, when the workload is too much, the targets are assigned at a high level, the work has high responsibility risks, work pressure is prone to cause money loss or going to prison, which makes the staff always stressed. Work pressure concerns aspects of the demands regarding the speed and workload (Pisanti et al., 2015; van Woerkom et al., 2016). Work pressure is certainly positively associated with physical and psychological (Pisanti et al., 2015) and absenteeism (Trybou et al., 2014; van Woerkom et al., 2016). Moreover, the regular introduction of modern technology has changed the method of working. It requires employees to adjust in order to adapt to new working conditions constantly. Most employees supposed they are suffering pressure from that changes-for example, overwork. Employees have too many tasks to complete on time, which is usually a real stress factor because they are expected to do their jobs for a certain amount of time but failed to achieve (Bashir and Ramay, 2010). 


\section{c. Time pressure}

Arnold, Robertson, and Cooper (1992) supposed working shifts and jobs that require them to work long hours affect their physical strength. Houtman and Jettinghoff (2007) cited factors such as working time, inflexible work time, overloading, and unpredictable working hours. Perlow (1999) revealed time shortage evidence, which remains a feeling of not having enough time to complete their working requirements for creativity. While some employees hold that it spurs them on to their best work, others say that it is almost impossible with such high performance. Therefore, this study examines the relationship between time pressure and job dissatisfaction. The author suggests that time pressure may precisely contain the type needed to do things creatively; however, it is created by satisfaction.

\section{d. Relationships pressure}

Working relationship means having multi-relationships in an environment with lots of working group interaction. People desperately need relationships to understand each other and work best with each other in groups. In my view, if the working environment is "hard," "cold," and lacks the support or assistance of colleagues and supervisors, employees will feel stifled and stressed. In fact, employees who suffer from poor working relationships with their supervisor, coworker, and subordinate will suffer from increased stress levels. Relationships with bosses, colleagues, and subordinates can significantly affect how employees feel. Superiors always pressurize to complete the work, the targets, or do not support employees when having difficulties, or unfairly evaluate employees. Randall, Cox, and Griffiths (2007) showed that poor management and the working environment without colleagues' support also contribute to stress. On the other hand, the fact is that VLEs currently have fierce competition, so the superiors always put pressure on employees to meet the set targets. Inadequate, unreliable, or unsupporting management interpersonal relationships, poor relationships with coworkers, working alone or the isolated establishment, and a lack of a complaint, they disagree on solving a problem or making a complaint increases the stress for employees.

\section{e. Job dissatisfaction}

Many previous scholars have revealed that job dissatisfaction is strongly related to the negative emotions of employees. Manifestations of dissatisfaction include depression, anxiety and avoidance, withdrawal, bladder, and indifferent feeling (Faragher et al., 2005). Dissatisfaction is a negative attitude of people who are working for any organization. In my opinion, job dissatisfaction is measured by basic indicators covering working conditions, compensation and benefits, training, and development opportunities. There are poor working conditions, work overload, low pay, no opportunity for promotion or career development, and a lack of recognition (based on Tett and Meyer, 1993). It is certainly approved that dissatisfaction is a negative attitude by turnover intention. When they are dissatisfied, they may quit the organization or stay at the organization but passively respond or have no contributions and ideas to develop their organizations. Therefore, employees are usually neglected 
instead of active attitude while working.

\section{f. Intention to leave or turnover intention}

Chen, Lin, and Lien (2010) supposed that a critical and challenging matter for personnel management is turnover intention. It is called conscious wilfulness to pursue other alternatives in other organizations (Applebaum et al., 2010). Turnover intention is concerned with dissatisfaction; in fact, once employees have a bad feeling, they will have no commitment and loyalty (Chen and Lin, 2011). In my opinion, some behaviors are considered to be quite obvious such as inattention to appearance, aggression with colleagues, being less willing to do special projects or frequent absence from staff meetings or working time, working late, or trying to avoid meetings, duties. They even decided to take a day off without any good reason. What should a personnel manager do when employees begin to show these behaviors? Having a focus on investing in the maintenance of talented employees in the short term. Organizations often deal with large-scale personnel changes to improve department or enterprise commitment, job satisfaction, and engagement. This strategy may work, but it takes time to design and implement. Keep thinking about employee instability, and a specific employee allows investing time and resources into those who create the most value and, in fact, are also at the highest risk of leaving.

\section{g. Relations of work tension, job dissatisfaction and ability to quit the job}

Countless previous scholars claimed that the larger the amount of stress that arises, the greater the employee's turnover intention increases (Chen et al., 2010; Applebaum et al., 2010). Noor and Maad (2008), Arshadi and Damiri (2013) revealed in their studies; there is a positive association between stress and turnover intentions. Dahmodharan and Arumugasamy (2011) confirmed that job stress has positively and directly affected job dissatisfaction. As a result, it leads to a reduction in their organizational commitment. It was remarkable that almost immediate determinants of turnover intentions came from a lack of satisfaction and commitment (Yang and Carayon, 2007). Joseph and Stacy (2004) confirmed a negative relationship between dissatisfaction and intention to leave. In general, to verify the relationship of three components in which the mediating role of dissatisfaction by the concerning literature, the author has expected to find out effects for connections between job dissatisfaction and job stress and turnover intention. Therefore, the following hypotheses have been developed for this research:

H1: Work stress is positively associated with job dissatisfaction.

H2: Timely stress is positively associated with job dissatisfaction.

H3: Relationship stress is positively associated with job dissatisfaction.

H4: Job dissatisfaction is positively associated with turnover intention. 
Figure 1. Initial model of the Effecting of job stress to intention leaving job of VLEs's employees

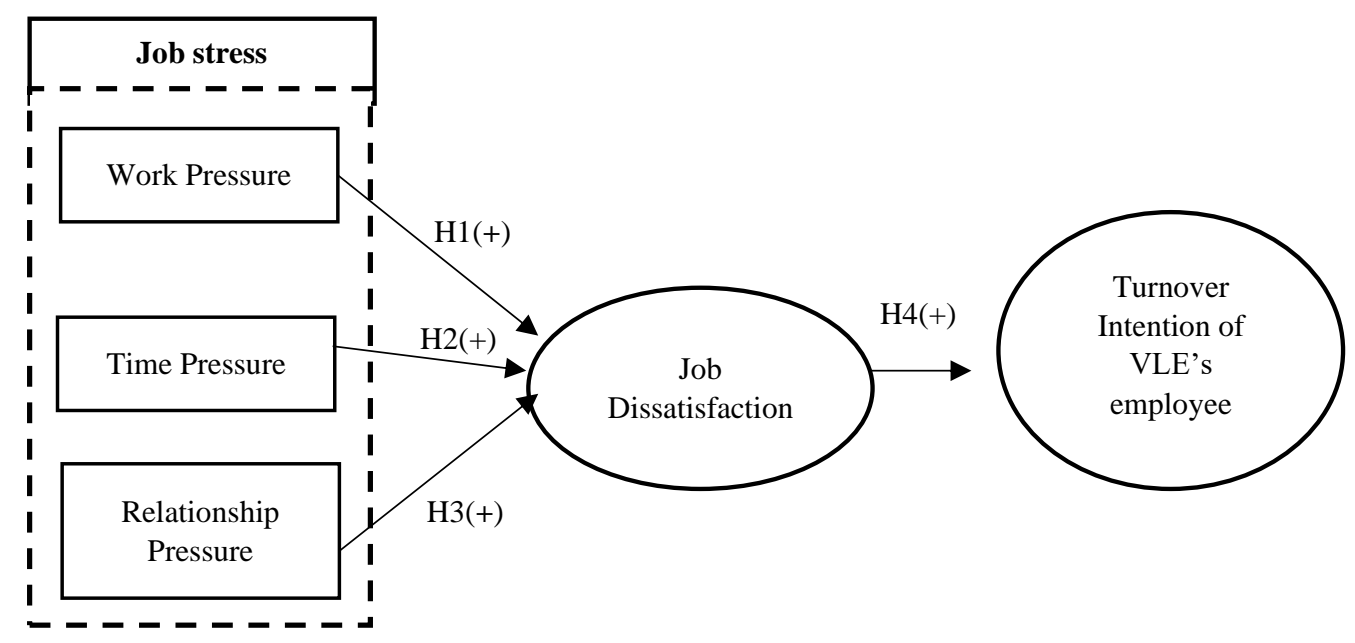

Source: The synthesis of qualitative studies by Author (2020).

\section{Research Methodology}

\subsection{Research Data}

This study surveyed staffs who are currently working at VLEs with following description enterprises: $31.7 \%$ of respondents surveyed of businesses with less than 50 employees; $19.5 \%$ of businesses from 50 to 100 employees and $17.1 \%$ of businesses from 101 to 200 employees, respectively rest of $9.8 \%$, for businesses more than 1000 employees. By the real situation of this industry, this statistic sample reflected exactly. There are logistics service providers among logistics enterprises that participated in the survey, including freight forwarding agents. To administer the stressor subscales of the Job Stress Index (JSI) (Sharma and Devi, 2011), the Intent to Quit scale (Mobley, Horner, and Hollingsworth, 1978 quoted by Tett and Meyer, 1993). Measuring the scale of job stress by using Likert 1 to 5 indicated disagreements to agree on each statement. To ensure the responses' credibility, the behavioral purpose should be measured within a realistic period after accepting a role within a company.

\subsection{Research Methodology}

This study uses qualitative and quantitative methods; these methods are used to test the veracity of a hypothesis that is carried out through data collection in the sector. Preliminary research is designed for both quality and quantity method. This analysis was conducted based on two methods: 
(1) Qualitative research aims at the realization and alteration of the scale components

(2) Quantitative research achieves the goals of collecting, studying primary data, testing of scale, accreditation of the initial model, and the hypothesis. Preliminary analysis, utilizing qualitative and quantitative techniques, is constructed and calibrated by the scale and attached to the observation variables. Experts carry out preliminary qualitative studies with great care, consideration, and group consultations with Logistics firms. The content of the discussion related to the factors that influence the turnover intention of employees at VLEs was presented together with the research model for the discussion group to comment on the factors affecting the purpose of the turnover and the draft scale generated by the group of writers and corrected by the discussion group. The discussion group agreed with the new model after an exchange of ideas. It is also recommended that the discussion group calibrate some of the names in the scale components and suggest changing the scale, changing some observed variables. As a result, the research group settled on the initial model of this analysis. To assess the reliability of the scale, "Exploratory Factor Analysis" is used to reduce data to a smaller collection of summary variables and investigate the underlying theoretical structure of the phenomenon. Official research is generated using the technique "Cronbach's Alpha." "Confirmatory Factor Analysis" evaluates whether a hypothesized measurement model is appropriate for the data. The definition of a theoretical causal model consisting of a collection of expected covariances between variables is "Structural Equation Modeling" and then tests whether it is plausible according to the observed results.

\section{Research Results}

Vietnam has been reached 300,000 logistics enterprises locating in areas with convenient transportation. According to VLA (2019), 38.8\% is allocated in the Red River Delta, $33.8 \%$ is distributed in the Southeast, $14.2 \%$ is allocated in the North Central and Central Coast, 5.6\% allocated in the Midlands and Northern, $5.2 \%$ is allocated in the Mekong River Delta, and $2.4 \%$ is allocated in the Central Highlands. Most of the capital size of businesses in this industry is low, less than 10 billion VND. Warehousing, freight forwarding, loading and unloading, sorting facilities, and packaging are specifically related to operational functions. Recently, there has been a significant increase in e-commerce logistics services, especially for the bulk, valueadded, food, and beverage trade. This poses a new challenge for the logistics workforce. In this study, the author surveyed employees who are working at logistics enterprises via convenient google forms. Data is collected in 8 weeks through an online survey with 331 accurate respondents. The collected data is converted to descriptive statistics, as shown in the table below. 
Table 1. Descriptive statistics of Representative sample

\begin{tabular}{clrr}
\hline Gender & Demographic feature & Frequency & Percentage \\
\hline \multirow{4}{*}{ Age } & Memale & 146 & 44.1 \\
& From 18 to less than 22 years & 165 & 49.9 \\
& old & 15 & 4.5 \\
& From 23 to less than 30 years & 106 & 32 \\
& old & & \\
& From 31 to less than 40 years & 152 & 45.9 \\
& old & & 12.1 \\
& From 41 to less than 50 years & 40 & 5.4 \\
& old & & \\
& From 50 years old and over & 18 & 1.6 \\
& & & 46.5 \\
Education & College & 5 & 51.9 \\
& University & 154 & 0.9 \\
& Postgraduate education & 172 & 59.2 \\
& & 3 & 32.3 \\
Income & $<7$ & 196 & 7.6 \\
(million & $8-10$ & 107 & 9.7 \\
VND) & $11-15$ & 25 & 14.5 \\
& $>15$ & 32 & 32.3 \\
& & & 22.4 \\
Years of & $<2$ & 48 & 21.1 \\
working & $2-5$ & 107 &
\end{tabular}

Source: Results of data analysis by Author (2020).

The research uses the scales of Arnold, Robertson, and Cooper (2009) and Bashir and Ramay (2010). "Work pressure" includes 5 observed variables, encoded from WPR1 to WPR5; "Timely pressure" of Robertson and Cooper (2009) includes 5 observed variables, encoded from TPR1 to TPR4); ); "Relationship pressure" of Randall, Cox, and Griffiths (2007) includes 4 observed variables, encoded from RPS1 to RPS4. This study refers to Joseph and Stacy (2004) used for "Job dissatisfaction" (including 5 observed variables, encoded from JD1 to JD5) and the scale of Gauci-Borda, and Norman (1997) is used to measure "turnover intention" (Including 4 observed variables, encoded from TOI to TOI4). Conducted pre-test "Work pressure," "Timely pressure," "Relationship pressure," "Job dissatisfaction" and "Turnover intention" scales all achieve the reliability; they are suitable for EFA analysis. 
Table 2. Cronbach's Alpha results

\begin{tabular}{lccc}
\hline \multirow{2}{*}{ Name of scale } & \multicolumn{2}{c}{ Number of items } & Cronbach's Alpha \\
\cline { 2 - 3 } Work pressure (WPR) & Before & After & \\
Timely pressure (TPR) & 5 & 5 & 0.913 \\
Relationship pressure (RPR) & 5 & 5 & 0.906 \\
Job dissatisfaction (JD) & 4 & 4 & 0.948 \\
Turnover Intention (TOI) & 5 & 5 & 0.952 \\
\cline { 1 - 2 } & 4 & 4 & 0.896
\end{tabular}

Source: Results of data analysis by Author (2020).

The results of EFA analysis reveals that there are five extracted factors which explain $73.413 \%$ among research variances and an eigenvalue value of 1.220. Thus, the next step to process data is CFA aiming to test the observed variables. In fact, CFA analysis results show that $\mathrm{TLI}=.962>.9, \mathrm{CFI}=.968>0.9$ and $\mathrm{RMSEA}=.059<.08$ are all fixed and $\mathrm{Cmin} / \mathrm{df}=2.163<5$ meet the criterion for compatibility. Additionally, Chi-squared is 419.554 with $\mathrm{df}=194, \mathrm{P}=0.000$ is allowed. 
Figure 2. Results of research

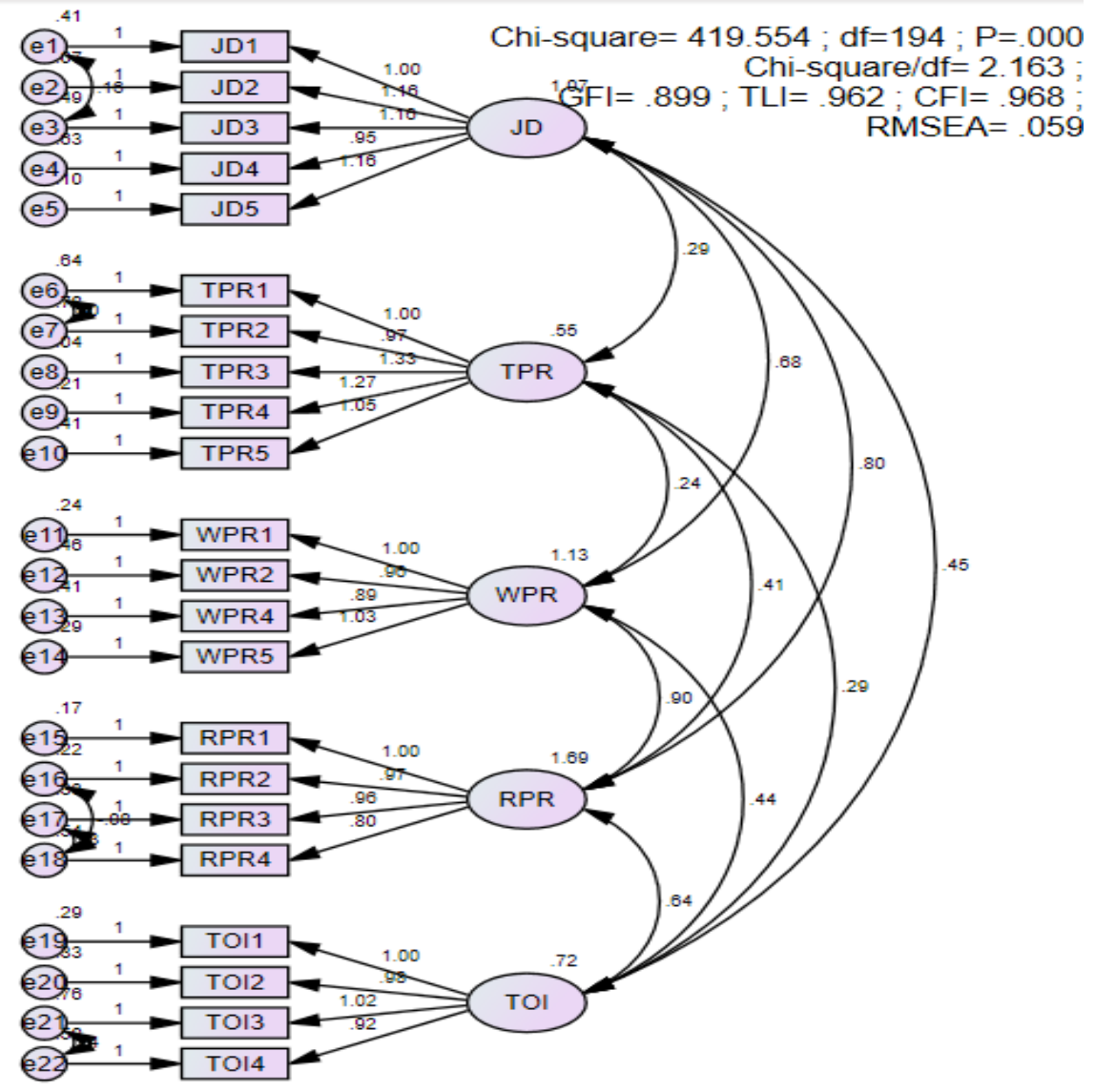

Source: Results of data analysis by Author (2020).

Table 3. Summary of scales testing results

\begin{tabular}{|c|c|c|c|c|c|}
\hline \multirow[b]{2}{*}{ Scales } & \multirow{2}{*}{$\begin{array}{l}\text { No. of } \\
\text { Items }\end{array}$} & \multicolumn{2}{|c|}{ Reliability statistics } & \multirow{2}{*}{$\begin{array}{l}\text { Variance } \\
\text { Extracted }\end{array}$} & \multirow[b]{2}{*}{ Validity } \\
\hline & & $\begin{array}{c}\text { Cronbach's } \\
\text { Alpha }\end{array}$ & Total & & \\
\hline Work pressue (WPR) & 5 & .913 & .75 & .92 & \\
\hline Timely pressure (TPR) & 5 & .906 & .65 & .90 & \\
\hline Relationship pressure (RPR) & 4 & .948 & .82 & .95 & Accepted \\
\hline Job dissatisfaction (JD) & 5 & .952 & .79 & .95 & \\
\hline Turnover Intention (TOI) & 4 & .896 & .61 & .86 & \\
\hline
\end{tabular}

Source: Results of data analysis by Author (2020).

This study specifically examined the effect of stress on the intention to leave. It investigated this theoretical model by using SEM to measure the impact of work stress on the turnover intention with the mediator of dissatisfaction factor, with stress 
being regularly cited as a major predictor of anticipated turnover. In previous studies, job stress had the strongest link to turnover intention, and the causes of this stress were identified as low autonomy, low recognition, and poor communication with colleagues (Hinshaw et al., 1987; Blegen, 1993). With the recent developments influencing the practice of logistics and the resulting rise in workforce demands, it is unsurprising that stress is still a concern for today's career. Also, particular stressors were not identified in the papers examined with consensus, although various stressors were identified as significant for some samples, such as workload (Yin and Yang, 2001) and unstable work schedules (Shader et al., 2001).

Table 4. Summary of hypotheses tests (Standardized)

\begin{tabular}{|c|c|c|c|c|c|c|c|}
\hline \multicolumn{3}{|c|}{ Hypotheses } & Estimation & SE & $\mathbf{C R}$ & P-value & Conclusion \\
\hline JD & $\begin{array}{l}<-- \\
-\end{array}$ & WPR & .392 & .059 & 6.422 & .000 & $\mathrm{H} 1$ is accepted \\
\hline JD & $\begin{array}{l}<- \\
-\end{array}$ & TPR & .132 & .067 & 2.755 & .000 & $\mathrm{H} 2$ is accepted \\
\hline JD & $\begin{array}{l}<- \\
-\end{array}$ & RPR & .293 & .049 & 4.711 & .000 & $\mathrm{H} 3$ is accepted \\
\hline TOI & $\begin{array}{l}<- \\
-\end{array}$ & JD & .545 & .044 & 8.699 & .000 & $\mathrm{H} 4$ is accepted \\
\hline
\end{tabular}

Source: Results of data analysis by Author (2020).

The findings have strongly confirmed that there is a tight relation within the 4 abovementioned factors. Similar to Joseph and Stacy's (2004) research, employees face unsatisfactory working conditions in several ways. Quitting and disengagement are the most common reactions to job frustration that have led some leaving work. Nevertheless, testing by SEM would show a clear and consistent relationship among nominated factors.

Figure 3. SEM results for the standardized model

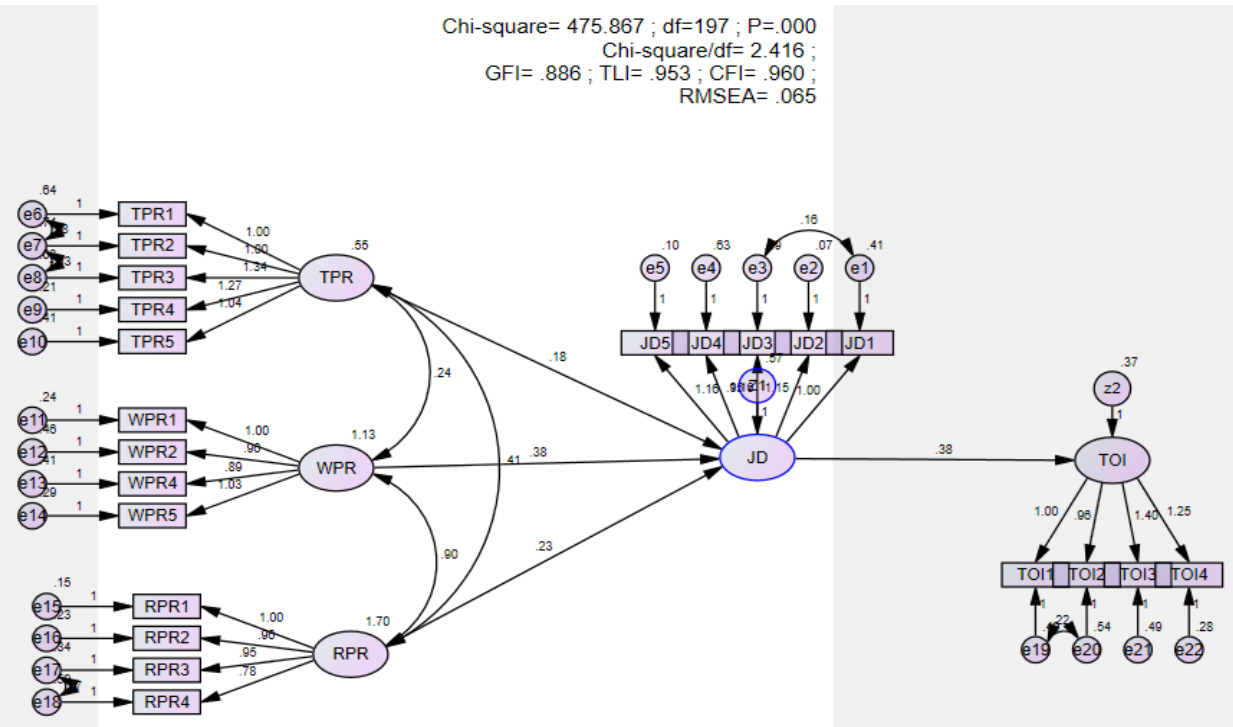

Source: Analyzed by Author (2020). 
The model is well fitted to the data $(\chi 2=2.416, \mathrm{df}=197, \mathrm{p}=.000, \mathrm{RMSEA}=.065, \mathrm{CFI}=.960$, $\mathrm{GFI}=.886, \mathrm{SRMR}=.014)$ and significantly explains how its components are related to each other. As can be seen, the turnover intention is directly influenced by job stress by fulfilling job dissatisfaction. The findings for internal consistency reliability (CR) values for all the constructs are as follows; TPR (.931), WPR (.951), RPR (.952), DS (.946), and TOI (.956). The value of composite reliability in each construct is acceptable between .931 to .956 , while a value greater than .60 is acceptable in exploratory studies (Gefen et al., 2000). Nevertheless, this value should be higher than 70 (Hair et al., 2011). The SEM value showed all items AVE $>.50$ are acceptable convergence value. The average variance extracted (AVE) gave scores of TPR (.801), WPR (.843), RPR (.832), DS (.851) and TOI (.786).

Finally, using bootstrap as alternative sampling, and the initial sampling is the crowd. The study uses the pattern $\mathrm{N}=1.000$. The variance is not statistically significant (Table 5). We can therefore infer that the model, as a result of the above, achieves reliability.

Table 5. Estimated results by bootstrap with $N=1000$

\begin{tabular}{|c|c|c|c|c|c|c|c|}
\hline \multicolumn{3}{|c|}{ Parameter } & SE & SE - SE & Mean & Bias & SE - Bias \\
\hline JD & $<---$ & TPR & .085 & .003 & .174 & .010 & .004 \\
\hline JD & $<---$ & WPR & .072 & .002 & .382 & .000 & .003 \\
\hline JD & $<---$ & RPR & .056 & .002 & .235 & .003 & .002 \\
\hline TOI & $<---$ & JD & .045 & .001 & .381 & .001 & .002 \\
\hline
\end{tabular}

Source: Results from the data process of Author (2020).

\section{Discussions}

"Work pressure" (WPR) has the highest effect on "Job dissatisfaction" (DS) with $\beta=.38$; it reveals work dissatisfaction of employees at SMEs. The second-highest impact on work pressure is "Relationship pressure" (RP) with $\beta=.23$. "Time pressure" also has an impact on DS with $\beta=.18$. The regression coefficient of Job stress (JS) has indirectly affected turnover intention (TOI): Work pressure*disatisfaction=.144. This demonstrates that the Work pressure and work frustration increase 1 when other variables stay the same; turnover intention increases by 0.144 . Likewise, the tension of relationship and work dissatisfaction increases 1 , turnover intention increases by 0.088 ; and Time pressure and job dissatisfaction increase 1 , turnover intention increases by 0.0684 . SEM results show that: Job stress, including Work pressure, Time pressure, and Relationship pressure, have a positive impact on job dissatisfaction. Thus, all hypotheses $\mathrm{H} 1, \mathrm{H} 2$, and $\mathrm{H} 3$ are accepted. Work dissatisfaction has a positive influence on the turnover intention, so hypothesis H4 is acknowledged. These research outcomes are quite similar to early researches of Alexandros et al. (2003), Joseph and Stacy (2004).

Research result shows that the more stressful the job is, the higher the employee's intention to change the job becomes. Besides, the research has identified the constituent factors that contribute to the logistics employee's job stress: work pressure, time pressure, and relationship pressure that affect turnover intention through dissatisfaction. Some 
suggestions proposed to help manage stress concerning the findings of this report, and to reduce the intention of logistics employees to leave, are as follows:

I. VLEs' administrators need to allocate work to the employee reasonably and pay attention to the current workload that employees are undertaking, thereby allocating time for new work, avoiding work overload, and creating a comfortable and gentle working atmosphere work pressure.

II. VLEs' managers should often improve working conditions, upgrade work support equipment, create a comfortable working space, and reduce too rigid rules. Simultaneously, the manager should also consider entertaining programs, such as annual company vacations, bonding workshops to maintain employees' healthy and positive spirit, creating a work connection between employees, and employees with leaders to build a friendly working environment.

III. VLE's managers need to open up a wide, sociable relationship with the team, thereby sharing the problems arising at work to relieve pressure and work overload. The employee must determine the personality and views of superiors and colleagues to have an appropriate approach and behavior, avoiding causing unnecessary misunderstandings. Also, friendliness, support, and respect for colleagues and superiors are indispensable requirements in a team. Furthermore, the difference in employees' feelings is likely to affect their behavior, so this research also finds contributions to a certain percentage of spending on organizational behavior practices, respectively.

In fact, the significance of Work Stress to Job dissatisfaction and Intention to leave is due to other factors that may cause changes in the measured variables, including demographics (characteristics of the research subject), other variables are likely to be related or by looking at the actual phenomenon occurring in the field. From the result of this research, the author can conclude that the employees' stress at VLEs in Vietnam is not because of their works, but it could be caused by other factors such as educational, cultural, family, religion, and other factors which require further research. For a long time, the concept of job dissatisfaction has been considered as a significant role in the outcomes of employees such as performance, creativity, and intention to quit job following different aspects. However, the author cannot find a standard theory of this situation instead of the behavioral and psychological impacts of dissatisfaction on the job. Therefore, the effects of work dissatisfaction and turnover intention considered by different stressors are implicit guides to further study in other industries.

\section{Conclusions}

The above analysis of the quantitative research results has confirmed the close relationship between job stress, dissatisfaction, and employee turnover intention. Consequently, it is necessary to study them using a deductive approach (comprises work pressure, time pressure, and relationship pressure), and job dissatisfaction and turnover intention were included. The findings confirm the positive relationships between negative emotions in the workplace connected to 
individuals' behavior. It shows that job stress is related to employee dissatisfaction and intention to leave; it is also consistent with other researchers' findings that the author mentioned in the above discussion. These results support the hypothesis that organizational behavior $(\mathrm{OB})$ patterns have a positive effect on individual behavior and broaden the literature in developing countries like Vietnam relating to human resource management. The study confirms and develops Arshadi and Damiri (2013) thesis about the centrality of reciprocity in terms of how relationships are improved by Gyamfi (2014). This is because the study's conceptual model's key property is that job dissatisfaction mediates the relationship between job stress and turnover intention. While extensive empirical research has been carried out connecting OB practices with employee behavior, there is still little explanation for how OB practices affect employee behaviors. The analysis of employee behaviors and their determinants can help formulate recommendations for personnel management. VLE's managers should consider using this relationship as a mediator between $\mathrm{OB}$ practices systems and employee behaviors. According to the research results, shaping employee behavior modifies the performance of individual employees and the organization. Because this study has shown that the OB practices resourcing, training, incenting, relationships have an effect on employee behavior, therefore, managers should pay more attention to ensuring that the clusters $\mathrm{OB}$ practices are clearer to employees, more comprehensible, and more meaningful (helping employees achieve goals in order to reduce turnover intention). Efforts are also necessary to raise the VLE's awareness of any employee response and to have prompt solutions such as allocating tasks, flexible working time, building a friendly environment to reduce negative pressure, increase satisfaction and raise commitment to their organizations. The pilot study seems to provide a solid starting point for future research with a larger, representative sample that is Logistics enterprises in Vietnam, which will investigate the fulfillment of dissatisfaction as a predictor of employee turnover intention and as a mediator between $\mathrm{OB}$ practices and employee behavior. Future studies should also concentrate on other sectors and contexts in different industries to validate and strengthen the current findings.

It is concluded that dissatisfaction with job stress is an issue related to work, time pressure, and relationship pressure. Remarkably, VLEs managers should address the different employees' roles and efforts that they truly contribute to their organization's success. From that, VLEs' managers know how to treat them well. The significance between Work stress to Job dissatisfaction and Intention to leave is due to those factors that may be the results of the measured variables, including demographics (characteristics of the research subject), other variables are likely to be related or by looking at the actual phenomenon occurring in the field. From the result of this research, it can be concluded that the stress faced by the employees at VLEs is mainly because of their works, but it also could be caused by other factors such as sex, income, education, and other factors which require further research. 


\section{References:}

Alexandros, A., et al. 2003. Occupational Stress, Job satisfaction, and health state in male and female junior hospital doctors in Greece. Journal of Managerial Psychology, 18(6), 592-621.

Anderson, C.R., et.al. 1977. Managerial responses to Environmentally induced stress. Academy of Management Journal, 20, 260-272.

Arnold, I., Cooper, L., Robertson, I.T. 1991. Work Psychology. London: Pitman Publishers.

ArshadI, N., Damiri, H. 2013. The Relationship of Job Stress with Turnover Intention and Job Performance: Moderating Role of OBSE, Procedia - Social and Behavioral Sciences, 706-710.

Bashir, U., Ramay, I. 2010. Impact of stress on Employees Job Performance: A Study On Banking Sector Of Pakistan. International Journal of Marketing Studies, 2(1), 122126.

Yang, C.L., Carayon, P. 2007. Effect of job demands and social support of worker stress: a study of VDT users, 2-40. Retrieved from: https://doi.org/10.1080/01449299508914623.

Chang-Yang., et al. 2015. Effects of job stress on self-esteem, job satisfaction, and turnover intention. Journal of Transnational Management, 21(1), 29-39(11).

Chen, M., Lin, C. 2011. Modelling job stress as a mediating role in predicting turnover intention. Service Industries Journal, 31(8), 1327-1345.

Chen, M.F., Lin, C.P., Lien, G.Y. 2010. Modeling job stress as a mediating role in predicting turnover intention. The Service Industries Journal, 1743-9507.

Dahmodharan, K., Arumugasamy, G. 2011. Effect of occupational stress on executives' leadership styles. Public policy and Administration Research, 1(4), 2224-573.

Darvish dan Sharbani. 2013. Study of The Relationship Between Job Stress and Intention to Leave the Nursing Profession, Advances in Nursing \& Midwifery, 22(79).

Gauci-Borda, R., Norman, I. 1997. Factors influencing turn-over and absence of nurses: a research review. International Journal of Nursing Studies, 34(6), 385-394.

Gibson, et.al. 2012, Organizations Behavior Structure Processes. New York: McGraw Hill General Statistics Office of Vietnam. Retrieved from: https://www.gso.gov.vn/default_en.aspx?tabid=774.

Gyamfi. 2014. Influence of Job Stress on Job Satisfaction: Empirical Evidence from Ghana, Police Service. International Business Research, 7(9). ISSN 1913-9004.

Hair, F.J., Ringle, M.C. 2011. PSM-SEM; Ineed the silver Bullet. The Journal of Marketing Theory and Practice, 9(2), 139-151. DOI: 10.2753/MTP1069-6679190202.

Houtman, I., Jettinghoff, K. 2007. Raising Awareness of Stress at Work in Developing Countries: A modern hazard in a traditional working environment, protecting workers-WHO. Health Series No. 6, Geneva.

Hsien-Che, L., Tsai-Hua. 2008. The impact of leadership styles on job stress and turnover intention Taiwan insurance industry as an example. Department of Business Management, Tatung University, Taiwan. PLS-sem: Indeed a silver bullet.

Joseph, R., Stacy, S. 2004. The effects of various personological traits on individuals' reactions to job dissatisfaction at differing levels of intensity. University of Colorado at Boulder.

Lu, H., Kuo, Y., 2016. The effect of job stress on self-reported safety behavior in container terminal operations: The moderating role of emotional intelligence. In: 
Transportation Research Part F Traffic Psychology and Behavior, 37, DOI: 10.1016/j.trf.2015.12.008.

Karunanithy, K., Ponnampalam, A. 2013. A study on the effect of stress on performance of employees in Commercial Bank of Ceylon in the Eastern Province. European Journal of Business and Management, 5(27), 87-95.

Randall, R., Cox, T., Griffiths, A., 2007. Participants' accounts of a stress management intervention. In: Human Relations, 60(8), 1181-1209. DOI: $10.1177 / 0018726707081660$.

Robbins, S. 2004. Organizational Behavior. Prentice Hall pub. Ed. 9th, USA.

Perlow, L.A. 1999. The time famine: Toward a sociology of work time. Administrative science quarterly, 44(1), 57-81.

Sharma, J., Devi, A. 2011. Role stress among employees: An empirical study of commercial banks. Gurukul Business Review, 7, 53-61.

Tett, P., Meyer, P. 1993. Job Satisfaction, Organizational Commitment, Turnover Intention, and Turnover: Path Analyses Based on Meta-Analytic Findings. Personnel Psychology, 46, 259-293. Retrieved from: http://dx.doi.org/10.1111/j.17446570.1993.tb00874.x.

Vietnam Logistics Associations. 2019. The current status of the Logistics workforce in Vietnam. Australian Aids by Autralia Government and Ministry of Fair in Vietnam. 